\title{
IDEAÇÕES DAS PRÁTICAS PEDAGÓGICAS DO PROFESSOR ADMINISTRADOR
}

\author{
IDEAS DE PRÁCTICAS PEDAGÓGICAS DEL PROFESOR ADMINISTRADOR
}

IDEAS OF PEDAGOGICAL PRACTICES OF THE TEACHER ADMINISTRATOR

\author{
Elaine Pontes BEZERRA ${ }^{1}$ \\ Silvana MALUSÁ ${ }^{2}$
}

RESUMO: Os cursos de Administração têm aumentado consideravelmente no Brasil nas duas últimas décadas, o que gera uma grande demanda por professores administradores. É relevante que estes profissionais, os quais não tiveram uma formação docente, sejam conscientes das questões que envolvem a sua prática docente, assim como as Instituições de Ensino Superior (IES), para que juntos consigam atender com êxito as demandas e expectativas da sociedade contemporânea. Assim, esse estudo que se trata do recorte de uma pesquisa de doutorado, tem como objetivo apresentar os resultados e discussão para a investigação realizada com professores bacharéis de Administração acerca das suas ideações de suas práticas pedagógicas.

PALAVRAS-CHAVE: Professor administrador. Prática pedagógica. Docência universitária.

RESUMEN: Las carreras de administración en Brasil han aumentado considerablemente en las últimas dos décadas, lo que genera una gran demanda de profesores administradores. Es relevante que estos profesionales, que no han tenido una formación docente, sean conscientes de los problemas relacionados con su práctica docente, así como de las Instituciones de Enseñanza Superior (IES), para que juntos puedan satisfacer con éxito las demandas y expectativas de la sociedad contemporánea. Por lo tanto, este estudio, que es un recorte de una investigación de doctorado, tiene como objetivo presentar los resultados y la discusión de la investigación realizada con profesores de licenciatura en administración sobre sus ideas sobre sus prácticas pedagógicas.

PALABRAS CLAVE: Profesor administrador. Práctica pedagógica. Enseñanza universitaria.

ABSTRACT: Business courses in Brazil have increased considerably in the last two decades, which generates a great demand for managing teachers. It is relevant that these professionals, who have not had a teacher education, are aware of the issues surrounding their teaching practice, as well as the Higher Education Institutions (HEIs), so that together

${ }^{1}$ Universidade Federal do Piauí (UFPI), Parnaíba - PI - Brasil. Professora Adjunta Departamento de Ciências da Administração e Informática. Doutorado em Educação (UFU). ORCID: https://orcid.org/0000-0003-3825-6741. E-mail: elainepontes@hotmail.com

${ }^{2}$ Universidade Federal de Uberlândia (UFU), Uberlândia - MG - Brasil. Professora Associada Departamento de Educação. Doutorado em Educação (UNIMEP). ORCID: https://orcid.org/0000-0002-1054-2036. E-mail: silmalusa@yahoo.com.br 
they can successfully meet the demands and expectations of contemporary society. Thus, this study, which deals with the clipping of a doctoral research, aims to present the results and discussion for the research conducted with bachelor of management professors about their ideas of their pedagogical practices.

KEYWORDS: Managing professor. Pedagogical practice. University teaching.

\section{Introdução}

O curso de Administração configura-se como um dos mais ofertados no Brasil. De acordo com o Instituto Nacional de Estudos e Pesquisas (INEP), no ano de 2008 haviam 549 cursos e, em seu último senso, realizado no ano de 2018, esse número aumentou expressivamente para 2.263 cursos no país.

Para este cenário, uma consequência é o aumento do número de professores de administração, onde muitos ingressam na carreira acadêmica sem um preparo mínimo para a docência, evidenciando-se uma necessidade por parte das IES e desses próprios profissionais em compreenderem os aspectos que norteiam a sua prática docente, para que contribuam na sociedade atual com uma educação superior eficaz.

Pimenta e Anastasiou (2014) dizem que na maioria das IES os professores mesmo experientes e conhecedores de suas áreas apresentam-se despreparados e sem conhecimento técnico acerca do processo de ensino e aprendizagem pelo qual são responsáveis no contexto educacional.

Muitos autores têm se dedicado à investigação da docência universitária, inclusive a respeito dos aspectos pedagógicos, como é possível verificar nos estudos de: Cunha (2018), Masetto (2015), Pimenta e Anastasiou (2014), Almeida (2012), Isaia (2006), Veiga (2007), Zabalza (2004), dentre outros.

Sobre os conhecimentos pedagógicos, este é "o ponto mais carente de nossos professores universitários [...] seja porque nunca tiveram oportunidade de entrar em contato com essa área, seja porque a veem como algo supérfluo ou desnecessário para a sua atividade" (MASETTO, 2015, p. 32). O autor considera ainda como fundamental para o exercício da profissão docente ser competente em alguma área específica de conhecimento e da dimensão política no ensino.

O professor administrador das universidades públicas, graduado em Administração, está nessa posição de quem não teve oportunidade de contato com a área pedagógica, e não 
domina os aspectos que Masetto (2015, p. 32, grifo do autor) considera como o grande eixo do processo ensino e aprendizagem, os quais são:

[...] o próprio conceito de processo de ensino-aprendizagem, a concepção e gestão de currículo, a integração das disciplinas como componentes curriculares, a compreensão da relação professor-aluno, a teoria e prática da tecnologia educacional, a concepção do processo avaliativo e suas técnicas de feedback, o planejamento como atividade educacional e política.

Assim, o professor administrador como tantos outros docentes graduados em áreas distintas da Educação enfrentam dificuldades para o exercício da sua profíssão.

Geralmente, a preocupação desse profissional está voltada para o domínio dos conteúdos e ele se esquece dos aspectos pedagógicos do seu trabalho, dedicando-se, principalmente, em estudar as teorias de sua área específica e/ou em desenvolver pesquisas. Fato é que esse docente além de não ter recebido uma formação pedagógica durante o período em que se formou profissionalmente, para ingressar na carreira acadêmica não lhe foi exigido legalmente qualquer formação pedagógica.

Ao iniciar na docência, o professor administrador se vê diante de uma realidade que não vivenciou e/ou conheceu durante a faculdade, além do ensino, ele depara-se com inúmeras atividades que envolvem também a pesquisa e a extensão, no mínimo.

Para Almeida (2012, p. 69), “a docência universitária caracteriza-se por ser um conjunto de ações que pressupõe elementos de várias naturezas, o que impõe aos sujeitos por ela responsáveis um rol de demandas, contribuindo para configurá-la como um campo complexo de ação".

O professor administrador precisa compreender melhor este tão complexo campo de ação, que é o da docência universitária, para que possa oferecer uma educação de qualidade aos seus alunos.

Para Veiga (2007, p. 33), essa qualidade pode ser alcançada se a docência for considerada mediante a visão profissional, como uma atividade especializada, "ela requer formação profissional para seu exercício: conhecimentos específicos para exercê-lo adequadamente ou, no mínimo, a aquisição dos conhecimentos e das habilidades vinculadas à atividade docente $[\ldots] "$ ".

Diante o exposto, é relevante investigar sobre as concepções da prática pedagógica por parte dos professores administradores, os quais tornaram-se docentes, sem formarem-se para a docência. 
Para tanto, o estudo tem como objetivo descrever as ideações que os docentes bacharéis de Administração, das Universidades Públicas do Piauí possuem acerca da sua prática pedagógica.

As respostas servirão como um norte para orientar docentes a compreenderem a complexidade e riqueza do seu trabalho, marcado por desafios e saberes próprios da docência. Ademais, essas respostas poderão ainda guiar as IES a desenvolverem ações institucionais que contribuam para uma docência universitária mais eficaz.

\section{Metodologia}

A investigação em questão, que se propõe a averiguar com o professor administrador quais são as suas ideações acerca da sua prática pedagógica, se inscreve em uma abordagem qualitativa.

Em um estudo qualitativo, pretende-se compreender a percepção dos participantes com relação aos fenômenos que os cercam, as suas experiências, opiniões e perspectivas ligadas a sua realidade vivenciada (SAMPIERI; COLLADO; LUCIO, 2013).

É um estudo com objetivo exploratório, uma vez que busca uma maior compreensão de uma temática não muito explorada, neste caso, a prática docente do professor administrador (MALHOTRA, 2011).

Trata-se também de um estudo com objetivo descritivo, tendo como procedimento a pesquisasurvey, pois busca a opinião de um grupo específico de pessoas, indicadas como representantes de uma população-alvo, por meio de questionário (BABBIE, 2005).

A população da pesquisa foi composta pelos docentes universitários efetivos, que lecionam no curso de Administração das universidades públicas do Estado do Piauí e, que necessariamente, tenham formação inicial em Administração, somam um total de 56 participantes. Obteve-se como amostra da pesquisa 51 respondentes, que de acordo com Bareta (2014) é representativa, para um nível de confiança 95\% e margem de erro 5\%, permitindo assim a generalização dos resultados.

O questionário foi desenvolvido e disponibilizado para os respondentes utilizando-se da plataforma Google Docs. Foi por meio das páginas web das universidades e dos diversos sites que continham periódicos de autoria da população que obteve-se os e-mails destos professores pesquisados. 
Após 15 dias do envio dos e-mails, foram realizados contatos telefônicos (informação obtida pela Pro-Reitoria de Graduação das universidades) com a população para obtenção de um retorno expressivo de respostas e em 45 dias encerrou-se a coleta. -

Para a análise dos dados, utilizou-se a técnica de análise de conteúdo temática. Decodificou-se os "dados brutos do texto por meio de recorte, agregação e enumeração" (BARDIN, 2016, p. 133). De forma a favorecer a percepção de novas interpretações a respeito das ideações do docente administrador sobre a sua prática pedagógica, na Educação Superior, utilizando-se de categorias de análise (BARDIN, 2016)

\section{Resultados e discussão}

Com a questão subjetiva Pedagogicamente, o que é ser docente do ensino superior? , determinou-se a categoria "Ser docente do ensino superior" e realizou-se o agrupamento das respostas que foram reunidas em seis (6) subcategorias, aqui descritas com as suas respectivas frequências: a) contribuir para a formação profissional e humana, $(f) 14$; b) comprometer-se com a aprendizagem do aluno, $(f) 13$; c) conciliar teoria e prática, $(f) 8$; d) formar para a criticidade, $(f)$ 8; e) ter compromisso social e político, $(f) 6$; f) exercer ensino, pesquisa e extensão, $(f) 6$.

Todos os 51 participantes $(\mathrm{P})$ responderam a questão, sendo que alguns expressaram a sua opinião que pode ser compreendida a partir de duas ou mais unidades de sentido, por isso, a soma da frequência das subcategorias ultrapassa o número de participantes. Evidenciou-se as unidades de sentido de cada resposta para posterior categorização (BARDIN, 2016).

\section{Contribuir para a formação profissional e humana}

Aqui segue-se alguns dos relatos pertencentes a esta subcategoria, a qual teve a maior frequência nas respostas:

É um formador da consciência profissional, pessoal e humana do cidadão. $(\mathrm{P}-4)$

Ser um cidadão que contribui com a formação profissional e desenvolvimento pessoal de outrem. (P-30)

É poder, através da comunicação e conhecimento na área, contribuir para a formação pessoal e profissional do aluno. (P-14) 
É contribuir para a formação de profissionais comprometidos com os aspectos humanos de forma autônoma e reflexiva com vistas a construir uma atuação ética e responsável. (P-33)

É contribuir para formação profissional do aluno, incentivar a aprofundar seus conhecimentos e estimular a alcançarem seus anseios. (P-21)

Esses professores consideram que ser docente é, a partir da sua prática pedagógica, contribuir não apenas para a formação profissional do aluno, mas também para a sua formação enquanto ser humano em diálogo com a sociedade a fim de transformá-la e modificá-la.

O docente administrador pode, em se pensando em uma educação voltada para a cidadania, desenvolver no aluno além de uma visão política, o seu potencial humano, o que contribuiria para o seu convívio em sociedade (KERSH, 2017).

Na proposição de Aktouf (2005), formar o aluno de Administração para humanidades juntamente com o desenvolvimento de uma cultura geral é tão importante quanto a educação em conhecimentos formais, sendo assim uma maneira de ativar a sensibilidade do mesmo nas e pelas relações empreendidas com o outro.

Aspectos da cidadania ou da cultura são alternativas propostas pelos autores mencionados (quais?), mas há também outras formas de se preparar o aluno para uma formação humana, como por exemplo, envolvendo-o em atividades extensionistas e de pesquisa que estejam atreladas às questões sociais, ambientais, políticas etc.

Formar o aluno para os aspectos humanos é desafiante. Pressupõe-se que o seja até mesmo para os professores que se formaram pedagogicamente, que cursaram uma licenciatura, os quais obtiveram conhecimentos das metodologias, da natureza e da sociedade a ensinarem, mas não obtiveram em sua formação como ensinar e aprender a serem humanos (ARROYO, 2013).

Porém, embora o professor não tenha obtido em sua formação a possibilidade de aprender e ensinar sobre humanidades, independente da sua área específica, ele precisa exercê-la enquanto professor e ser humano, diante das circunstâncias diversas de vida e de trabalho. 


\section{Comprometer-se com a aprendizagem do aluno}

Algumas das respostas que se sobressaíram para esta subcategoria:

É estar preparado para participar ativamente do processo ensinoaprendizagem. (P-37)

Ser um facilitador do processo de ensino-aprendizagem. (P-38)

É estar preparado para ser um facilitador da aprendizagem do aluno. (P-13)

É saber reconhecer o que deve ser transmitido ao aluno levando em consideração não só questões teóricas, mas sobretudo dentro dessa teoria o que realmente vai gerar impacto positivo e aprendizagem significativa. (P36)

\section{[...] tornar as aulas ambiente de ensino aprendizado. (P-16)}

Com essas afirmações os docentes demonstraram a noção de que é necessário um envolvimento com o processo de ensino e aprendizagem, no sentido de reunir esforço em torno da melhoria da aprendizagem dos discentes, algo que revela o compromisso com a profíssão professor, bem como com os aspectos sociais, culturais, econômicos, dentre outros, que envolvem a formação do administrador.

Pensar no ensino, implica também refletir, agir sobre o processo de ensino e aprendizagem, havendo uma articulação concreta destas duas dimensões, pois elas se complementam e seguem de forma interdependente. $\mathrm{O}$ ensino não existe sem a aprendizagem (ZABALZA, 2004; FREIRE, 1996). É preciso “[...] ensinar a partir do respeito à aprendizagem do aluno" (ISAIA, 2006, p. 76). Ou seja, daquilo que já sabe, aprendeu das suas vivências e das suas experiências nos e em outros lugares sociais (familiar, religioso, mídias, dentre outros).

Ao docente administrador sem formação pedagógica compete-lhe um grande desafio, que é o de oferecer um ensino com qualidade, o qual segundo Zabalza (2004), só é possível quando se compreende o processo de ensino e aprendizagem. Entende que a aprendizagem na educação é "um processo de aquisição de conhecimentos, desenvolvimento de habilidades e mudança de atitudes em decorrência de experiências educativas, tais como aulas, leituras, discussões, pesquisas, etc." (GIL, 2018, p. 80).

Em vista disso, o docente administrador mesmo não dominando os conhecimentos pedagógicos, pode estar envolvido com a aprendizagem do seu aluno através das estratégias de ensino para o processo de ensino-aprendizagem. 
Dentre as estratégias de ensino, tem-se como exemplo constante nas salas de aula dos cursos de Administração: o estudo dirigido, o estudo de caso, os jogos empresariais, os seminários, os casos para ensino, a pesquisa de campo etc. Essas ações permitem a concretização de um envolvimento comprometido com a docência. De acordo com Freire (2007, p. 15) "Compromisso seria uma palavra oca se não houver a decisão lúcida e profunda de quem o assume".

\section{Conciliar teoria e prática}

Para os professores pesquisados, ser docente do ensino - Educação Superior (termo cunhado a partir da LDB 9.394/1996 - numa perspectiva democrática da educação) é considerar em sua função os aspectos da teoria e prática que cercam - ou envolvem? o fazer docente, conforme se pode verificar nas respostas:

Dotar o aluno de conhecimentos teóricos e práticos, competências e habilidades necessárias para o desenvolvimento da profissão. (P-11)

É alinhar a prática profissional a teoria e desenvolver os alunos em sala de aula [...]. (P-17)

Conciliar teoria com prática, além de provocar a reflexão e senso crítico dos alunos. (P-29)

O professor deve trabalhar os conhecimentos teóricos e práticos de forma conjunta, assim como seu "discurso sobre Teoria deve ser exemplo concreto, prático, da Teoria" (FREIRE, 1996, p. 48). Desta maneira, é importante que o docente administrador se aproprie das teorias específicas da área da Administração. Na mesma direção ele também deve estar atento às práticas cotidianas exigidas ao administrador. Em suas aulas, é imprescindível desenvolver estratégias de ensino que permitam ao seu aluno compreender a relação das teorias com a prática profissional. Isto, pois quando o aluno consegue assimilar a relação entre teoria e prática, ele aprende (ZABALZA, 2004).

Santos et al. (2016) sugerem que o docente administrador pode estabelecer a relação da teoria e da prática em seu ensino através dos estudos de casos empresariais, levando os seus alunos a saírem dos muros da universidade e a realizarem visitas em organizações para conhecerem de perto o seu funcionamento. A integração teoria/prática faz parte das competências pedagógicas do docente (ISAIA, 2006). O professor administrador, que possivelmente não domina essas competências, pode além do uso das estratégias de ensino, 
contribuir para esta integração com o uso de exemplos trazidos de suas outras práticas profissionais fora da universidade.

Conforme é ressaltado por Cunha (2018, p. 128), quando discute os resultados de sua investigação ligada ao "Bom Professor", realizada com professores universitários e de escola técnica, este assinala que:

O domínio do conteúdo é um valor ressaltado pelos professores e está bastante relacionado com a prática profissional fora da escola ou da universidade, pois é ela que define a possibilidade de relacionar a matéria de ensino com a prática. Ajuda a dar exemplos e favorece a maior instrumentalização do aluno para trabalhar com a realidade.

\section{Formar para criticidade}

Os professores pesquisados acreditam que ser docente é formar alunos de maneira a despertá-los para o senso crítico, como verifica-se nas seguintes respostas:

Ser capaz de despertar o senso crítico dos alunos para as questões da cotidianidade, fazendo-o refletir para tomar decisões práticas no âmbito profissional [...]. (P-34)

Contribuir com a construção do pensamento crítico. (P-10)

Colaborar efetivamente para a formação profissional de um aluno, despertando nele a capacidade crítica. (P-18)

Diante desse mundo com tanta riqueza de informações, é essencial ao indivíduo desenvolver um "grande espírito crítico, competência que inclui o hábito de se questionar perante o que lhe é oferecido" (ALARCÃO, 2018, p. 14). Destarte, o professor tem como um de seus maiores desafios, o de auxiliar no desenvolvimento do espírito crítico dos seus alunos, e isso "faz-se no diálogo, no confronto de ideias e de práticas, na capacidade de se ouvir o outro, mas também de se ouvir a si próprio e de se autocriticar" (ALCARÃO, 2018, p. 34).

Assim, o professor universitário deve a partir das suas práticas pedagógicas, conduzir diálogos e levantar discussões que envolvam os seus alunos em questões cotidianas, orientando-os a refletirem e a se posicionarem de forma questionadora mediante as informações e conhecimentos que recebem frequentemente. Ademais, para exercer o papel de formador para a criticidade, esse professor deve ainda se perceber e refletir sobre as suas ações docentes, de forma crítica.

Maranhão (2010, p. 153) reforça que para formar administradores na perspectiva da criticidade é necessário propor uma formação não limitada a reprodutibilidade e que motive o 
aluno a "refletir sobre suas ações no âmbito social" e o estimule "a questionar as realidades humanas naturalizadas e vislumbrando outras formas de se organizar o mundo".

Docentes administradores precisam formar alunos para a criticidade. $\mathrm{O}$ meio organizacional demanda por profissionais capazes de refletir e agir criticamente, de maneira a atuarem como profissionais conscientes das realidades que o cercam e que saibam modificálas, interferindo positivamente nas questões sociais, políticas, ambientais, dentre outras.

\section{Ter compromisso social e político}

Descreve-se a seguir as respostas mais significativas desta subcategoria:

[...] É saber que a formação transborda as barreiras da sala de aula e deve estar atrelada à realidade social, cultural, econômica, política e ambiental dos diferentes estudantes e suas realidades [...]. (P-6)

Saber transmitir conhecimento e buscar crescimento, evolução, dos alunos, no sentido de uma cidadania plena. (P-7)

É está aberto a descobrir as novas demandas de saberes e intermediar junto aos alunos uma formação mais coerente com as necessidades do ambiente econômico, social, cultural, político, ambiental, etc. na atualidade. (P-40)

Considerar a perspectiva política para a docência é uma maneira de desenvolver o compromisso social do professor, somadas as dimensões técnica e pedagógica (CORREA et al., 2011). Ensinar é complexo e demanda além da compreensão da área específica de ensino, requer uma captação do "seu significado social” (PIMENTA, 2011, p. 08).

Ter o domínio dos conhecimentos específicos e pedagógicos é essencial ao exercício da docência, mas é necessário ainda que o professor seja consciente do seu papel social e político que exerce através da sua profissão. Ele deve considerar em sua prática pedagógica o contexto que circunda professor, aluno e instituição de ensino.

Dentro dessa perspectiva, considerar o contexto, significa fazer os alunos conhecerem as diversas realidades sociais, culturais, ambientais, econômicas, políticas etc. Mas esse conhecer precisa estar além da perspectiva de apenas tomar conhecimento sobre a realidade, é preciso que o docente desperte nos seus alunos um olhar crítico desta. É imprescindível que o professor instigue esses alunos a pensarem estrategicamente, por exemplo, de que maneira eles poderiam através da sua futura atuação profissional interferir de maneira construtiva para a mudança de cenários indesejáveis.

O docente administrador forma futuros profissionais que atuarão em organizações que afetam o funcionamento da sociedade em geral, inclusive em suas necessidades desde 
algumas mais básicas, como é o caso da saúde e educação. Escolas, hospitais, organizações não governamentais, espaços públicos em geral etc., precisam de gestores com uma percepção mais voltada para a cidadania, como citado por P-7, de maneira que possam ser capazes de transformar a realidade social dos indivíduos que dela fazem parte.

\section{Exercer o ensino, pesquisa e extensão}

No que se refere a subcategoria "Exercer o ensino, pesquisa e extensão", descrevem-se os seguintes relatos a seguir:

[...] ser docente é contribuir para a formação acadêmica dos seus discentes, desenvolvendo atividades que vão além do ensino, com a extensão e a pesquisa, por exemplo [...]. (P-3)

É ser o tipo de profissional que trabalha com ensino, pesquisa e extensão objetivando contribuir para a formação, da melhor maneira possível, das demais profissões [...]. (P-22)

Nas IES com cursos de Administração que propõem apenas o ensino, "o conhecimento administrativo torna-se rígido e estático", pois sem a pesquisa não é possível conhecer os mecanismos da administração, tornando impossíveis os ajustes, e os conceitos são apenas reproduzidos (NICOLINI, 2003, p. 53).

O ensino de administração efetivo deve apresentar-se na perspectiva do caráter investigativo (pesquisa) e das ações extencionistas para que possa desenvolver-se de acordo com as realidades locais, e não mais como uma mera reprodução de ensino advindo de outras nações com realidades distintas das do Brasil. Para tanto, é importante que o docente universitário não fique à mercê das condições ideais para exercer o tripé ensino, pesquisa e extensão.

O docente pode, por exemplo, articular-se com outras instituições e profissionais da esfera pública e/ou privada, colegas da instituição pertencentes a outros cursos, programas da rede municipal, estadual e/ou federal etc.

Em conjunto com essas instituições, o professor pode obter informações a respeito da situação local e/ou regional e ter um acesso mais próximo à realidade que o circunda, para articular as suas ações de ensino, pesquisa e extensão, de maneira que possa a partir disso, intervir na realidade social com a sua prática docente.

Quando o professor exerce uma prática docente que integra a pesquisa e a extensão, oferece uma maior possibilidade de mobilização dos saberes coletivos de alunos e docentes. 
Além disso, cabe apontar que a pesquisa favorece uma ruptura nas concepções tecnicistas de docência, além de permitir novas percepções da relação entre teoria e prática (FRANCO, 2009).

\section{Considerações finais}

A partir da análise de conteúdo proposta por Bardin (2016), com as respostas obtidas para a categoria "Ser docente do ensino superior", a discussão e análise das subcategorias encontradas na pesquisa permitem-nos algumas considerações finais.

O docente administrador, mesmo tendo uma formação advinda de uma ciência social aplicada, é consciente de que o seu aluno deve estar preparado de maneira profissional, mas que os aspectos das humanidades precisam ser tratados em sala de aula também. Inferindo-se que este professor exerce uma prática pedagógica que supera a racionalidade técnica ainda tão presente em áreas como a Administração.

Para os professores participantes da pesquisa, a docência é um compromisso com a aprendizagem do aluno. Certamente, estes profissionais desenvolvem uma prática docente pautada em estratégias de ensino que contribuem para o processo de ensinoe aprendizagem, o que não deve ser tarefa fácil para estes atores sociais, pois não tiveram uma formação pedagógica.

Por outro lado, sabe-se que estes professores podem buscar meios para desenvolverem saberes específicos da docência e, então, exercerem um ensino de qualidade e comprometido com a profisssão docente.

Ficou evidente que os docentes pesquisados concebem a docência de maneira atrelada ao exercício de conciliar teoria e prática. Preocupam-se em exercer uma prática pedagógica de maneira a facilitar para o aluno de administração a compreensão dos elementos das teorias a partir das situações práticas reais, com criticidade e ainda ligadas ao mercado de trabalho para o administrador. São docentes que, certamente, se preocupam com e exercem uma prática docente fazendo o uso da conciliação entre teoria e prática.

Os professores acreditam também que ser docente é formar para a criticidade, preocupam-se em despertar os seus alunos para o senso crítico, o que requer além da reprodução de conhecimentos meramente técnicos. O meio organizacional da atualidade demanda por gestores também conscientes das questões humanas, sociais, culturais, ambientais, políticas etc., que reflitam e ajam criticamente. 
O compromisso social e político está presente nas ideações das práticas pedagógicas pelos docentes administradores. Há uma preocupação em formar alunos advertidos dessas questões. Assim, considerar estes aspectos que assolam a sociedade como um todo, permite ao professor atuar como agente social, formando profissionais mais completos, coerentes com a realidade e que estarão mais preparados para transformar de maneira positiva o meio organizacional e a vida das pessoas.

Não menos importante foi a última subcategoria identificada que é exercer ensino, pesquisa e extensão, demonstrando que os docentes administradores estão conscientes da natureza das suas práticas pedagógicas, se dispondo em oferecer uma formação menos tecnicista, mais contextualizada, e através da mobilização de saberes entre docentes e discentes.

Face ao exposto, o docente administrador compreende a docência da Educação Superior a partir de uma prática pedagógica bastante centrada no aluno, o que é positivo, pois demonstra o seu compromisso com a docência. Porém, a figura do professor é imprescindível na importante via de mão dupla da educação, que é o processo de ensino e aprendizagem.

O professor pesquisado parece dar uma ênfase menor a si próprio nesse processo de ensino e aprendizagem, pois não coloca nas suas ideações sobre a docência da Educação Superior, os imprescindíveis conhecimentos necessários à docência, que são os específicos da sua área de formação inicial e os pedagógicos, embora tenha considerado a sua dimensão política da prática pedagógica.

\section{REFERÊNCIAS}

AKTOUF, O. Ensino de Administração: Por uma pedagogia para a mudança. Organizações \& Sociedade, Salvador, v. 12, n. 35, p. 151-159, out./dez. 2005.

ALARCÃO, I. Professores reflexivos em uma escola reflexiva. 8. ed. São Paulo: Cortez Editora, 2018.

ARROYO, M. G. Ofício de mestre: imagens e auto-imagens. 15. ed. Petrópolis: Vozes, 2013.

BABBIE, E. Métodos de Pesquisas de Survey. Belo Horizonte: Editora UFMG, 2005.

BARBETTA, P. A. Estatística aplicada às ciências sociais. Florianópolis: Ed. UFSC, 2014.

BARDIN, L. Análise de conteúdo. São Paulo: Edições 70, 2016.

BRASIL. Instituto Nacional de Pesquisas Educacionais. Ministério da Educação. Sinopses Estatísticas da Educação Superior. Brasília, DF: INEP/MEC. Disponível em: 
http://inep.gov.br/web/guest/sinopses-estatisticas-da-educacao-superior. Acesso em: 13 de dez. 2018.

CORRÊA. A. K. et al. Formação pedagógica do professor universitário: reflexões a partir de uma experiência. In: PIMENTA, S. G.; ALMEIDA, M. I. (Org.). Pedagogia universitária: caminhos para a formação de professores. São Paulo: Cortez, 2011. p. 75-102.

CUNHA, M. I. O bom professor e sua prática. 24. ed. São Paulo: Papirus, 2018.

FRANCO, M. A. S. Prática docente universitária e a construção coletiva de conhecimentos: possibilidades de transformações no processo ensino aprendizagem. Cadernos Pedagogia Universitária, Universidade de São Paulo, Pró Reitoria de Graduação, set. 2009.

FREIRE, P. Educação e mudança. 30. ed. São Paulo: Paz e Terra, 2007.

FREIRE, P. Pedagogia da autonomia: saberes necessários à prática educativa. São Paulo: Paz e Terra, 1996.

GIL, A. C. Didática do ensino superior. 2. ed. São Paulo: Atlas, 2018.

ISAIA, S. M. A. Desafios à docência superior: pressupostos a considerar. In: RISTOFF, D.; SEVEGNANI, P. (Org.). Docência na educação superior. Brasília, v. 5, 2006. p. 63-84.

KERCH, A. L. A formação de administradores no Brasil e a educação para a cidadania: reflexões acerca de uma possível intersecção. In: Encontro Nacional dos Cursos de Graduação em Administração, 28., 2017, Brasília. Anais [...]. Brasília, DF: Universidade Federal do Rio Grande do Sul, 2017.

MALHOTRA, N. K. Pesquisa de marketing: uma orientação aplicada. 6. ed. Porto Alegre: Bookman, 2011.

MARANHÃO, C. M. S. A. Indústria cultural e semiformação: análise crítica da formação dos administradores. Orientadora: Ana Paula Paes de Paula. 2010. 249 f. Tese (Doutorado em Administração) - Faculdade de Ciências Econômicas, Universidade Federal de Minas Gerais, Belo Horizonte, 2010.

MASETTO, M. T. Competências pedagógicas do professor universitário. São Paulo: Summus, 2015.

NICOLINI, A. Qual será o futuro das fábricas de administradores? Revista de Administração de Empresas-RAE, v. 43, n. 2, abr./maio/jun. 2003.

PIMENTA, S. G. (Org.). Saberes pedagógicos e atividade docente. 4. ed. São Paulo: Cortez, 2005.

PIMENTA, S. G.; ANASTASIOU, L. G. C. Docência no ensino superior. São Paulo: Cortez, 2014.

SAMPIERI, R. H.; COLLADO, C. F.; LUCIO, M. P. B. Metodologia de pesquisa. 5. ed. Porto Alegre: Penso, 2013. 
SANTOS, G. L. S.; MELO JÚNIOR, D. F. A.; SÁ, N. M. N.; MELO, T. P. O Ensino da Administração e o desafio de unir teoria e prática. Uma análise organizacional da AESGA, alicerçados, apenas, nas disciplinas vivenciadas no $1^{\circ}$ período. In: CONGRESSO INTERNACIONAL DE ADMINISTRAÇÃO, 2016, Natal. Anais [...]. Natal, RN: ADM, 2016.

VEIGA, I. P. A. Profissão professor até quando? Pleiade, Foz do Iguaçu, v. 1, n. 1, p. 29-40, jul./dez. 2007.

ZABALZA, M. A. O ensino universitário: seu cenário e seus protagonistas. Porto Alegre: Artmed, 2004.

\section{Como referenciar este artigo}

BEZERRA, E. P.; MALUSÁ, S. Ideações das práticas pedagógicas do professor administrador. Revista Ibero-Americana de Estudos em Educação, Araraquara, v. 16, n. 2, p. 539-553, abr./jun. 2021. e-ISSN: 1982-5587. DOI: https://doi.org/10.21723/riaee.v16i2.13151

Submetido em: 23/11/2019

Revisões requeridas em: 10/07/2020

Aprovado em: 30/10/2020

Publicado em: 01/02/2021 